Ksenija Vulović

Universidad de Belgrado

\title{
El tiempo en las ciudades míticas de la literatura hispanoamericana: Macondo, Comala y Santa María
}

Palabras clave: ciudad mítica, Cien años de soledad, Pedro Páramo, El astillero, tiempo cíclico, tiempo estático, tiempo fragmentario

\section{Introducción}

Muy a menudo en los textos críticos sobre Gabriel García Márquez, Juan Rulfo y Juan Carlos Onetti las ciudades imaginarias que crearon estos autores se denominan como ciudades míticas. Sin embargo, son pocos los críticos que intentan explicar qué es lo que determina la naturaleza mítica de Macondo, Comala y Santa María. Nuestro objetivo es tratar de determinar la naturaleza específica del tiempo como una de las características fundamentales de estas ciudades míticas, en el ejemplo de las novelas Cien años de soledad de Gabriel García Márquez, Pedro Páramo de Juan Rulfo y El astillero de Juan Carlos Onetti.

Antes de todo, es necesario precisar qué se entiende por naturaleza general de las ciudades míticas. A su vez, esta cuestión plantea otras preguntas esenciales: ¿qué es un mito y qué es una ciudad?

Tanto el tema del trabajo como su carácter, impiden exponer en detalle el desarrollo del pensamiento filosófico acerca del concepto de mito, o definiciones diferentes de la noción de la ciudad. Será suficiente señalar que la definición de ciudad puede englobar la ciudad como un conjunto de personas, la naturaleza de las relaciones interpersonales y sociales, en otras palabras, la organización y normas específicas de la vida dentro de una localidad, no sólo sus características espaciales o históricas. 
El entendimiento del concepto de mito ha cambiado profundamente durante distintos períodos históricos, y dependía en gran medida si el enfoque al concepto fue filosófico, sociológico, psicoanalítico, antropológico o literario ${ }^{1}$. Para los propósitos de nuestro trabajo vamos a intentar reducir algunas de estas percepciones del mito a una determinación amplia en el contexto de la literatura. Por lo tanto, el mito sería un tipo de relato sobre cómo una cierta realidad llegó a su existencia (Elijade, 1998: 8). En cuanto al tipo de realidad que se presenta en el mito, distinguimos los mitos cosmogónicos, escatológicos, los mitos sobre la caída, el diluvio, la muerte de los dioses, etc. Lo sobrenatural y lo fantástico en el mito figuran en los protagonistas que son seres sobrehumanos o deidades (Fraj, 1991: 49-50), pero también en la naturaleza del tiempo mítico que no se parece al tiempo histórico como lo conocemos en la vida cotidiana. El tiempo mítico presenta una excepción que se encuentra fuera del flujo temporal, es cíclico o no conoce las barreras entre los fragmentos de tiempo. Por otro lado, el espacio mítico no conoce las limitaciones reales de geografía y física. Por ejemplo, las distancias geográficas reales llegan a ser sobredimensionadas o desproporcionadamente cortas. La causalidad mítica no se basa en la relación tradicional entre causa y efecto, sino en la similitud de cualquier tipo, en el contacto establecido entre dos elementos.

Por último, si recordamos que la noción de ciudad la hemos entendido como un conjunto de localidad y totalidad de vida en ella, se hace evidente que, cuando la definición de mito comprendida de la manera previamente expuesta tratamos de aplicar a la ciudad como el lugar de los mitos, ese sitio adopta inevitablemente características de los parámetros espaciales, causales, éticos y temporales del universo mítico.

\section{Macondo}

El problema del tiempo en Cien años de soledad es uno de los más estudiados en la crítica literaria en cuanto a esta novela. Entre muchos críticos literarios que han examinado este tema, se encuentran, por ejemplo, Katalin Kulin, Roberto González Echevarría, Eugenia Neves, Vargas Llosa, Tzvetan Todorov y Giuseppe Bellini. Sus conclusiones son muy variadas, pero todos están de acuerdo en una: el tiempo en esta novela de García Márquez no se asemeja al

1 Para un panorama general del desarrollo histórico del pensamiento filosófico sobre el mito, en el que nos hemos basado en la elaboración de este ensayo, véase Meletinski (1983): Poetika mita. 
tiempo cotidiano. Algunos consideran ese tiempo como ahistórico, mientras que otros lo observan como cíclico. Estas dos opiniones diferentes sobre el tiempo en Cien años de soledad son en realidad los principales argumentos de la suposición acerca de su carácter mítico, ya que su naturaleza cíclica y ahistoricidad son las características fundamentales del tiempo mítico.

La naturaleza cíclica del tiempo en Cien años de soledad se manifiesta en el retorno de los acontecimientos a su principio o en la repetición de los mismos. Es verdad que cada repetición de los sucesos presenta necesariamente la vuelta a su principio. Sin embargo, con la separación de los dos conceptos queremos hacer una distinción entre el retorno al principio como un regreso no seguido de otro acontecimiento, sino de un retorno al estado de cosas tal como estaban antes de cierto evento, como si no hubiera pasado nada, y la repetición de algunos eventos en su totalidad o solo en una parte.

El retorno al principio aparece al final de la novela, cuando un ciclón borra Macondo de la faz de la tierra dejándolo como si nunca hubiera existido. No obstante, los acontecimientos se repiten en cada generación sucesiva. Así los hermanos, José Arcadio Segundo y Aureliano Segundo, comparten la misma amante, Petra Cotes, al igual que hacían su padre Arcadio y su tío Aureliano con Pilar Ternera. José Arcadio Segundo, con la huelga en la que participa, en su fracaso, repite el destino del coronel Aureliano Buendía y su participación en treinta y dos guerras civiles.

El acontecimiento más importante que se repite, pero con efectos diametralmente distintos, es el incesto. Al mismo tiempo, el incesto presenta una especie de marco de todos los eventos en la novela, abriendo y cerrando la historia de Macondo. A pesar del significado de este leitmotiv en el contexto del tiempo cíclico, es importante el hecho de que el incesto es un elemento esencial del mito. En muchas mitologías los ancestros son un hermano y una hermana, por lo que el primer matrimonio es incestuoso (Meletinski, 1983: 203).

Nos acordamos de que la primera relación incestuosa se realiza entre José Arcadio Buendía y Úrsula Iguarán, y exactamente esa relación presenta el momento iniciador en la historia de Macondo. Debido a las consecuencias de miedo de dar a luz a una iguana o a un niño con cola de cerdo que siente Úrsula, José Arcadio y Úrsula abandonan Riohacha y fundan Macondo. De ahí que el incesto es responsable de la creación de Macondo. Después de muchas generaciones que no podían olvidar la amenaza de cola de cerdo, Aureliano Babilonia y su tía Amaranta Úrsula engendran al último Buendía, el pequeño 
Aureliano con cola de cerdo. Amaranta Úrsula muere, las hormigas comen al niño, Aureliano Babilonia logra descifrar los escritos de Melquíades y revela el destino de su familia en la que está escrito que el linaje Buendía va a desaparecer con un niño con cola de cerdo, arrastrado por un viento horrible junto con toda la ciudad de Macondo. De esa forma el incesto cierra la última página de la historia de los Buendía y de Macondo también.

Los eventos en la novela de García Márquez se repiten en el nivel de lo cotidiano, los gitanos visitan el pueblo «todos los años, por el mes de marzo» (García Márquez, 2007: 9), y cada miembro de la familia Buendía «repetía todos lo días, sin darse cuenta, los mismos recorridos, los mismos actos, y que casi repetía las mismas palabras a la misma hora» (García Márquez, 2007: 283).

Además de los eventos, los nombres de los personajes principales y sus rasgos de carácter se repiten también (Kulin, 1973: 678). La repetición de los nombres reafirma a su vez la impresión del carácter cíclico, y por consiguiente mítico, del tiempo.

En cada generación del linaje Buendía se producen en alguna forma los siguientes nombres masculinos: José Arcadio y Aureliano, y femeninos: Úrsula, Amaranta o Remedios. Asimismo, los personajes que comparten el mismo nombre, comparten ciertas características: «Mientras los Aurelianos eran retraídos, pero de mentalidad lúcida, los José Arcadio eran impulsivos y emprendedores, pero estaban marcados por un signo trágico» (García Márquez, 2007: 212). Esta observación de Úrsula se confirma de generación en generación, desde el coronel Aureliano Buendía, luego con Aureliano José, hasta Aureliano Babilonia, y desde José Arcadio Buendía, después con José Arcadio y Arcadio. El único caso en el que esta regla no se aplica son los gemelos José Arcadio Segundo y Aureliano Segundo. Ni siquiera su madre podía diferenciar entre los hermanos, pero Úrsula tenía una convicción firme de que sus nombres habían sido sustituidos al nacer. Sin embargo, esta «irregularidad» en cuanto a los nombres fue corregida en su muerte cuando se confundieron los ataúdes y los gemelos fueron enterrados en las tumbas equivocadas, o mejor dicho, correctas. En cuanto a los personajes femeninos la repetición de los nombres está presente, pero rara vez la sigue la repetición de los caracteres. Este tipo de repetición solamente se nota en Úrsula Iguarán y Amaranta Úrsula, que heredó la fuerza de su personalidad.

Es interesante que ninguno de los nombres de los personajes episódicos aparece sólo una vez en la novela. Si el nombre de alguien se ha mencionado, 
este personaje sin duda va a reaparecer en la novela una vez más para describir un pequeño «círculo».

Tenemos que recalcar que los personajes femeninos muy a menudo son conscientes del carácter cíclico del tiempo. Ya hemos mencionado una observación de Úrsula en cuanto a la repetición de las actividades cotidianas. Igualmente, en el momento cuando José Arcadio Segundo empieza a interesarse por la huelga de obreros, ella nota: «Lo mismo que Aureliano. [...] Es como si el mundo estuviera dando vueltas» (García Márquez, 2007: 338). Cuando habla con José Arcadio Segundo que, igual que su tío, se había retirado al cuarto de Melquíades, Úrsula nota de nuevo que «el tiempo no pasaba, como ella lo acababa de admitir, sino que daba vueltas en redondo» (García Márquez, 2007: 381). Otra mujer consciente de que el tiempo anda en círculos es Pilar Ternera y el narrador dice sobre ella:

No había ningún misterio en el corazón de un Buendía, que fuera impenetrable para ella, porque un siglo de naipes y de experiencia le había enseñado que la historia de la familia era un engranaje de repeticiones irreparables, una rueda giratoria que hubiera seguido dando vueltas hasta la eternidad, de no haber sido por el desgaste progresivo e irremediable del eje. (García Márquez, 2007: 448)

Otro procedimiento en la estructuración de la novela que atribuye a la impresión del carácter cíclico del tiempo se relaciona con la conciencia del narrador. A esos procedimientos que el narrador utiliza Eva Lukavska los llama «la anticipación y la repetición». Así, al principio de un ciclo narrativo, como una introducción a la historia, el narrador omnisciente nos revela las últimas palabras o pensamientos del protagonista de ese ciclo narrativo y con una referencia a esas mismas palabras o pensamientos al final del ciclo narrativo se crea la impresión de existencia de carácter cíclico del tiempo y de su densificación (Lukavská, 1990: 52).

Sin embargo, no podemos descartar la posibilidad de la presencia de características opuestas en el tiempo de la novela de García Márquez. A la naturaleza cíclica de tiempo, según ciertos autores, se opone su estatismo. Críticos como Eugenia Neves, Roberto González Echevarría y Tzvetan Todorov han indicado que el tiempo se detiene en el cuarto de Melquíades. González Echevarría encuentra la razón de este fenómeno en dos líneas de acción separadas, cada una con su tiempo propio. La primera línea se 
relaciona con la familia Buendía y tiene su culminación en el momento del nacimiento del niño con cola de cerdo, mientras que la segunda línea se refiere al intento de descifrar los pergaminos de Melquíades y presenta una historia lineal que culmina cuando Aureliano Babilonia, por fin, traduce los pergaminos (González Echevarría, 1984: 371). En el cuarto de Melquíades el tiempo se detiene y se libera de esta inmovilidad sólo en los momentos de la interpretación de los pergaminos de Melquíades, según Eugenia Neves (1972: 182). Los personajes masculinos de Cien años de soledad son conscientes de la inmovilidad del tiempo en el cuarto de Melquíades. Por lo tanto, José Arcadio y el coronel Aureliano Buendía se dan cuenta de que allí siempre es martes. Muchos años después de la muerte de Melquíades, José Arcadio Segundo y Aureliano Babilonia encontraban a Melquíades en su cuarto, como si el tiempo se hubiera detenido para él, como si ni siquiera la muerte lo hubiera podido mover.

Eva Lukavska revela un rasgo interesante en la oposición entre el tiempo estático y el tiempo cíclico. Ella denomina el tiempo estático como masculino y con eso desea poner de relieve que la soledad y el aislamiento que sienten los personajes masculinos se proyectan en la imagen del tiempo estático. Debido a la incapacidad de realizar sus ideas en el presente (José Arcadio no logra entender en totalidad las invenciones que traen los gitanos, el coronel Aureliano no logra vencer en sus guerras, José Arcadio Segundo no tiene éxito en la huelga, etc.), los personajes masculinos se centran exclusivamente en el futuro y no son conscientes del flujo de tiempo. Por otro lado, el tiempo cíclico es femenino. Los personajes femeninos están inmersos en el presente. Para ellas, el pasado es el presente que ya ha ocurrido, y el futuro es el presente que va a suceder. Los hombres viven en un momento en el futuro que nunca va a ocurrir, y ellos, a diferencia de las mujeres, no se dan cuenta de que ciertos eventos se repiten constantemente (Lukavská, 1990: 54-55).

Otra característica fundamental con la cual el tiempo en Cien años de soledad se acerca a un tiempo mítico, es su ahistoricidad. Los procedimientos que García Márquez utiliza para representar el tiempo ahistórico en su novela, son muy diferentes. Los anacronismos se producen entre ellos (Rodríguez Monegal, 1972: 35-36). Así al mismo tiempo que los piratas ingleses del siglo XVI, vive el Duque de Marlborough. A los habitantes de Macondo les encanta el hielo o un invento como el imán, aunque podríamos concluir que viven en el siglo XIX o a los principios del siglo XX. De esa manera el tiempo de Macondo «sale» de los marcos históricos de su época, o no obedece la continuidad histórica 
de los acontecimientos. Tenemos que subrayar que el carácter cíclico del tiempo aporta a la impresión de la atemporalidad y ahistoricidad de la novela, sustituyendo la continuidad de los acontecimientos progresiva, necesaria para la noción de la historia, con un retorno eterno nietzscheano.

\section{Comala}

Cuando hablamos sobre Comala parece importante destacar que el tiempo en esta ciudad es determinado por el hecho de que en Comala habitan los muertos. El mismo Juan Rulfo, en su conversación con Joseph Sommers, dice que los muertos no tienen tiempo ni espacio (citado según: Durán, 1981). Cristina Fiallega sostiene que la colocación de un evento en el tiempo se define conforme a su posición, anterior o posterior, con otros acontecimientos (Fiallega, 2007: 115). En la muerte ya no existen pasado ni futuro, por lo tanto tampoco existe el tiempo presente. En la muerte no hay antes ni después, tampoco abora. Así que en la muerte, ergo en Comala también, existe únicamente la eternidad. La eternidad no pertenece al tiempo profano, histórico, sino al tiempo sagrado. No pertenece al mundo cotidiano, sino al mítico. La verdad es que en Pedro Páramo existen algunos elementos del tiempo histórico que se relacionan con la Revolución mexicana, pero ellos no influyen en la atmósfera general de esta obra que no tiene nada que ver con lo profano.

En ese sentido Carlos Fuentes intenta explicar la estructura fragmentaria de la novela en cuanto al tiempo de cada fragmento (Fuentes, 1981). El tiempo de cada segmento está en yuxtaposición con el tiempo de otros segmentos. Cuando el tiempo de unas palabras «Más te vale, hijo» (Rulfo, 2003: 85) vuelve nueve páginas después de ser enunciadas, comprendemos que estas palabras no están separadas por el tiempo, sino que tienen lugar en el mismo momento, que son las mismas palabras. Entre estos dos enunciados, aparentemente, no pasó nada o lo que ocurrió fue simultáneo con este anunciado.

En muy pocas palabras vamos a presentar la estructura de la novela con el fin de demostrar cómo la estructura participa en la creación de la impresión del tiempo cíclico, característico del mito. Pedro Páramo comienza y termina con la muerte, la muerte de los padres de Juan Preciado. Al inicio de la novela, Juan recuerda las promesas hechas a su madre moribunda, y al final de la novela vemos la muerte de su padre, Pedro Páramo. Sin embargo, poco después de su llegada a Comala, Juan Preciado se entera de que su padre había muerto, y sólo al final de la novela nos enteramos de cómo él murió, de que lo había matado el 
mismo hombre que al principio de la novela había anunciado a Juan la muerte de su padre. De esa manera, este hombre aparece al principio y al final de la novela, él inicia y cierra el círculo. En las primeras páginas, Abundio guía a Juan Preciado a Comala y le informa de que su padre había muerto y en las últimas páginas Abundio asesina a Pedro Páramo. Llegamos a ser conscientes de la paradoja en la cronología de los eventos, lo cual anula la linealidad y con un desplazamiento de los acontecimientos lógicamente increíble, crea una impresión de carácter cíclico de los mitos.

\section{Santa María}

Cuando hablamos sobre Santa María, es esencial subrayar una vez más que no vamos a tener en cuenta toda la saga santamariana sino solamente la obra maestra de Onetti, El astillero. Mientras Onetti en una serie de obras literarias con el tema de Santa María crea sin duda un mundo mítico, El astillero por sí mismo permite una perspectiva doble en la interpretación. Al mismo tiempo las características de Santa María se pueden considerar elementos de la simbolización mítica o las podemos percibir como recursos con los que el autor quiere contribuir al carácter ficticio de su obra.

Una sensación profunda de fragmentación del tiempo es el resultado de la impresión de la fragmentación del argumento de la novela. En efecto, muchos acontecimientos se mencionan por primera vez en los capítulos que no llevan el nombre de los sitios donde tienen lugar esos eventos, sino que se desarrollaron posteriormente en los capítulos a los que pertenecen por su nombre. De igual modo, la relación entre los acontecimientos basada únicamente en el espacio, crea una impresión de separación o alejamiento de los eventos, y por lo tanto, de su fragmentación. Además de la fragmentación del tiempo que conduce a la desestabilización de flujo temporal propio de los mitos, en El astillero Onetti nos sugiere que el tiempo es también ahistórico. El ejemplo más destacado de ahistoricidad de tiempo se presenta en la existencia de dos finales alternativos de la novela y en el hecho de que el autor no favorece ninguno de ellos.

\section{Conclusión}

Una mitificación del mundo, conmovedora y extraordinaria, llevada a cabo por Gabriel García Márquez, Juan Rulfo y Juan Carlos Onetti en sus novelas debía influir en la naturaleza del tiempo en ellas. Más allá de una naturaleza 
del tiempo cíclica, estática o fragmentaria, en ella, como en un prisma, se reflejan todas las características fundamentales de las mitologías modernas de estos grandes escritores. Leyendo estas novelas nos trasladamos del tiempo cotidiano en el que vivimos a un tiempo de mitos estetizado. Este tiempo a la vez nos libera y enaltece, ampliando nuestro horizonte de la experiencia,

y nos evoca un deseo cuya realización no podríamos experimentar de otra manera.

\section{Bibliografía}

Becerra, E. (1991): «Santa María de Onetti: autodestrucción y ficción literaria». En: Anales de Literatura Hispanoamericana, 20, 219-241: http://revistas.ucm. es/fll/o2 104547/articulos/ALHI9191110219A.PDF (31-03-2011).

Castañeda Hernández, M. C. (2009): «Pedro Páramo: ¿ficción o deconstrucción del mito?». En: Espéculo, Revista de estudios literarios, 42: http://www.ucm. es/info/especulo/numero42/pparamo.html (31-03-2011).

Durán, M. (1981): «La obra de Juan Rulfo vista a través de Mircea Eliade». En: Revista de literatura bispánica, 13: http://digitalcommons.providence.edu/ inti/vol1/iss13/5 (31-03-2011).

Elijade, M. (1998): Mit i zbilja. Belgrado: Plato.

Eyzaguirre, L. (1980): «Santa María: privado mundo imaginario de Onetti». En: Texto Crítico, 18-19, 196-203: http://cdigital.uv.mx/handle/123456789/6954 (10-08-2011).

Fiallega, C. (2007): «Los muertos no tienen tiempo ni espacio: el cronotopo en Pedro Páramo». En: Pol Popovic Karic, Fidel Chávez Pérez (coords.), Juan Rulfo: perspectivas críticas. México: Instituto Tecnológico de Estudios Superiores, 117-136.

Fraj, N. (1991): «Mit, pripovedačka književnost i pomeranje». En: Nortrop Fraj, Mit i struktura. Sarajevo: Svjetlost, 36-6o.

Franco, J. (1980): «La máquina rota». En: Texto Crítico, 18-19, 33-46: http://148.226.12.104/handle/123456789/6930 (10-08-2011).

Fuentes, C. (1981): «Mugido, muerte y misterio: el mito de Rulfo». En: Revista Iberoamericana, 116-117, 11-21: http://revistaiberoamericana.pitt.edu/ojs/ index.php/Iberoamericana/article/view/3636/3809 (04-08-2011).

García Márquez, G. (2007): Cien años de soledad. Madrid: Real Academia Española, Asociación de Academias de la Lengua Española, Alfaguara. 
González Echevarría, R. (1984): «Cien años de soledad: The Novel as Myth and Archive». En: Modern Language Notes, 2, 358-380: http://www. jstor. org/stable/2906193 (31-03-2011).

Gullón, R. (1972): «García Márquez o el olvidado arte de contar». En: Helmy Giacoman (ed.), Homenaje a Gabriel García Márquez: variaciones interpretativas en torno a su obra. Nueva York: Las Américas, 141-170.

Kulin, K. (1973): «Cien años de soledad. Aspectos de su mundo mítico». En: Anales de Literatura Hispanoamericana, 2, 677-685: http://revistas.ucm.es/ index.php/ALHI/article/view/ALHI7374110677A/25124 (31-03-2011).

Kulin, K. (1980): «Carácteres y estructura en El astillero de J. C. Onetti». En: Giuseppe Bellini (dir.), Actas del VII Congreso de la Asociación Internacional de Hispanistas, 649-656: cvc.cervantes.es/literatura/aih/pdf/o7/aih_07_2_011. pdf (31-03-2011).

Lukavská, E. (1990): «Gabriel García Márquez: El ciclo de Macondo II». En: Sborník Prací Filozofické Fakulty Brněnské Univerzity, 20, 49-62: www. phil.muni.cz/plonedata/wurj/erb/volumes-11-20/lukavska9o.pdf (3103-2011).

Martínez, P. (1983): «Técnica de la muerte en la crónica mítica de Rulfo». En: A. David Kossoff et al. (coords.), Actas del VIII Congreso de la Asociación Internacional de Hispanistas, 2, 259-264: cvc.cervantes.es/literatura/aih/ pdf/o8/aih_08_2_032.pdf (31-03-2011).

Meletinski, E. M. (1983): Poetika mita. Belgrado: Nolit.

Neves, E. (1972): «El zapatito roto de García Márquez». En: Revista Chilena de Literatura, 5-6, 171-195: http://www.jstor.org/stable/40355901 (04-082011).

Onetti, J. C. (1995): El astillero. Madrid: Cátedra.

Robles, M. (1990): «Fórmulas de estatismo en 'El astillero' de Juan Carlos Onetti». En: Revista Chilena de Literatura, 36, 121-127: http://www.jstor. org/stable/40356594 (31-03-2011).

Rodríguez Monegal, E. (1972): «Novedad y anacronismo de Cien años de soledad». En: Helmy Giacoman (ed.), Homenaje a Gabriel García Márquez: variaciones interpretativas en torno a su obra. Nueva York: Las Américas, 1342.

Rovira, J. C. (2005): Ciudad y literatura en América Latina. Madrid: Síntesis.

Rulfo, J. (2003): Pedro Páramo. Madrid: Cátedra. 
Todorov, T. (1982): «Macondo en París.» En: Peter Earle (ed.), Gabriel García Márquez. Madrid: Taurus, 104-113.

Vargas Llosa, M. (2007): «Cien años de soledad. Realidad total. Novela total.» En: Gabriel García Márquez, Cien años de soledad. Madrid: Real Academia Española, Asociación de Academias de la Lengua Española, Alfaguara, XXV-LVIII.

Villegas Posada, G. A. (1978): «Pedro Páramo o el mecanismo de codificación de un mito.» En: Thesaurus, 33, 1, 87-95: cvc.cervantes.es/lengua/thesaurus/ pdf/33/TH_33_001_087_o.pdf (31-03-2011). 
Ksenija Vulović

University of Belgrade

\section{Time in the mythical Cities of Latin American Literature: Macondo, Comala and Santa María}

Keywords: mythical city, One Hundred Years of Solitude, Pedro Paramo, The Shipyard, cyclic time, static time, fragmentary time

In the paper we address the issue of time in mythical cities in the works One Hundred Years of Solitude by Gabriel García Márquez, Juan Rulfo's Pedro Paramo and The Shipyard by Juan Carlos Onetti. First, we try to give a definition of the notion of the mythical city and the specific nature of its time. Then we investigate the following issues: relations between different presentations of the time (linear, cyclic, static), the repetition of events, the elements of its ahistoricity, the elimination of differences between past, present and future and the analogy with the concept of eternity in myth, the ambiguity between death and life that is based on the mythical concept of death and the fragmentation of time. In García Márquez's Macondo, linear time of Melquiades's room intertwine with cyclic time of the fiction. In Juan Rulfo's Comala, the boundaries between life and death are erased and there is a common time for all. In Onetti's Santa María, the fragmentary nature of time influences its perception and the fact that there are two alternate endings to the novel attests to the ahistoricity of time. 
Ksenija Vulović

Univerza v Beogradu

\section{Čas v mitičnih krajih hispanoameriške književnosti: Macondo, Comala in Santa María}

Ključne besede: mitični kraj, Sto let samote, Pedro Páramo, Ladjedelnica, ciklični čas, statični čas, fragmentarni čas

V članku avtorica obravnava temo časa v mitičnih krajih del Sto let samote Gabriela Garcíe Márqueza, Pedro Páramo Juana Rulfa in Ladjedelnica Juana Carlosa Onettija. Najprej poskuša definirati pojem mitičnih krajev in njihovih značilnosti v določenem obdobju, nato pa raziskuje naslednja vprašanja: odnose med različnimi časi (linearnim, cikličnim, statičnim), ponavljanje dogodkov, elemente ahistoričnosti časa, odpravo razlik med preteklostjo, sedanjostjo in prihodnostjo ter analogije med pojmom večnosti v mitu, dvoumnostjo med smrtjo in življenjem, ki temelji na mitičnem pojmu smrti, in časovno fragmentarnostjo. V Macondu Garcíe Márqueza se linearni čas Melquíadesove sobe prepleta s cikličnim časom fikcije, ki vsebuje ahistorične elemente, v Comali Juana Rulfa so meje med življenjem in smrtjo zabrisane, tako da obstaja en skupen čas za vse, v Onettijevi Santa Maríi pa fragmentarni čas vpliva na njegovo percepcijo in dejstvo, da obstajata dva možna konca romana, priča o njegovi ahistoričnosti. 